\title{
RESEARCH AND EVALUATION
}

\section{Organising for Effective Emergency Management: Lessons from Research ${ }^{1}$}

\author{
Arjen Boin \\ Utrecht University and Louisiana State University
}

\author{
Paul 't Hart \\ Australian National University and Utrecht University
}

\begin{abstract}
The February 2009 bushfires have prompted a debate with regard to contemporary arrangements for dealing with large-scale disasters. In this article, we seek to contribute to that debate by culling lessons learned from the literature on crisis and disaster management. We discuss what constitutes an effective disaster response system, we identify some key barriers to the effective functioning of such a system, and offer some suggestions for improvement.
\end{abstract}

Key words: bushfires, emergency, crisis management, response performance

\section{Introduction: Learning from Catastrophic Events}

The Black Saturday bushfires of February 2009 did not just shake the Australian nation, they also have led to a thorough rethinking of firefighting and emergency management arrangements in and beyond the state of Victoria. Coming on the heels of the Canberra 2003 bushfires, which also exposed hitherto unsuspected vulnerabilities in long-standing institutions and practices, the Black Saturday fires were an instance of a 'mega-disaster' (bigger in scope, more dynamic, more destructive, more uncontainable than 'routine emergencies'), that experts have been warning are on the rise. The deaths of more than 170 people in these fires and the massive physical and psychological damage they inflicted were unprecedented, shocking, and quickly deemed unacceptable. With such big losses surely something must have gone wrong. The search for culprits was on, as well as the search for lessons to prevent the recurrence of such runaway fires as well as to improve the robustness of emergency management systems more generally. The Bush- fire Royal Commission, which reported in June 2010, was the chief vehicle for this dual quest.

This article seeks to contribute to the wider lesson-drawing process triggered by the Victorian bushfires. It places the bushfire response process in the broader context of crisis management: preparing for and responding to unscheduled, undesirable, urgent and threatening contingencies. Emergency management (often also called crisis management) encompasses a whole range of such critical contingencies (as opposed to incidents) - not just megafires nor only natural disasters but the full range of major disturbances that can victimise, paralyse and traumatise societies, for example, pandemics, infrastructure breakdowns, terrorist attacks and outbursts of mass violence. Such contingencies are of the low probability but very high impact kind before they happen, posing challenges of risk management and preparedness. When they do happen, they tend to tax and defy existing response routines, resources and capabilities.

In the public eye, the Victorian system has been tried and found wanting during the 
bushfires. But is that really the case, or is it a case of hindsight biases and unrealistic standards and expectations regarding the capacity of governments to mitigate and respond to such mega-emergencies? How, in effect, do we make sure we learn sensible and feasible lessons from the bushfire experience, rather than outragedriven unhelpful ones? This article reflects on these questions. It reflects on the question of what constitutes achievable best (or good) practice in crisis management, and distils some general principles and lessons for approaching that best practice.

Two caveats are in order. First, we use the terms emergency, crisis and disaster interchangeably, though sometimes subtle conceptual distinctions are made between them by theorists, as well as practical distinctions in corporate and governmental regulations and planning documents. For our purposes, however, all terms refer to large-scale, threatening, urgent and uncertainty-filled disruptions of the status quo in a community or organisation. Second, there is not enough sufficiently 'hard science' (rigorous, comparative research covering the great number of possibly relevant conditions and variables at play) to confidently produce a failure-proof set of universally applicable organisational models, governance arrangements and behavioural principles. In what follows, we focus on areas where the findings of crisis research are most robust. We mine existing (international) research about principles and practices of effective crisis and emergency management.

\section{Effective Crisis Management: How Do We Know It When We See It?}

We speak of a crisis when a threat is perceived against the core values or life-sustaining functions of a social system, which requires urgent remedial action under conditions of deep uncertainty (Rosenthal, Charles and 't Hart 1989). Crises and disasters are 'inconceivable threats come true' - they tax our imagination and outstrip available resources. Policymakers typically experience crises as 'rude surprises' that defy conventional administra- tive or policy responses and cause collective stress (LaPorte 2007). They differ in scale, scope or complexity from the standard contingencies that have occurred in the past and for which they have prepared. A full-scale crisis presents policy-makers with dilemmas that have impossible-choice dimensions: everybody looks at them to 'do something', but it is far from clear what that 'something' is or whether it is even possible without causing additional harm.

Crises and disasters - including bushfires have always been with us, but it appears their character is changing. In fact, it is often argued that the crises of the near future will be increasingly frequent and generate higher impact (OECD 2003; Perrow 2007). Some agents of adversity have changed, creating new challenges for crisis management. In addition, the forces of modernisation have made our societies more prone to experience large-scale disturbances (Turner 1978; Perrow 1984; Beck 1992), in particular through growing complexity and tighter coupling of social, corporate, industrial, financial, infrastructural and administrative systems. This produces unforeseen disturbances that can assume previously inconceivable shapes and proportions. Under such pressure, it is easy to make wrong decisions that fuel rather than dampen the crisis at hand. Secondly, the societal and political climate in which political leaders and public agencies must operate today has made it harder to deal with crises and disasters ('t Hart 1993; Rosenthal 1998). Politicians and citizens display low tolerance for even minor disturbances, but at the same time they show little interest in efforts to improve crisis management. Yet when a crisis actually occurs, the search for scapegoats is on, amplified by a media all too willing to help identify the responsible parties. This creates an environment in which crisis management rapidly spills over into blame avoidance (Boin, McConnell and 't Hart 2008).

Public organisations tend to prepare for known and expected contingencies, but the administrative toolbox for routine disturbances has only limited use in the face of a major crisis (Lagadec 2009). The centralisation of authority and added layers of coordination often 
foreseen in crisis plans do not necessarily improve operational response capacity. Effective crisis management depends on principles and processes that assure flexibility and a smooth flow of information; formal structures play a facilitative role at best.

\section{Evaluating Crisis Response Performance}

Most crises and disasters pose recurrent response challenges. How well these challenges are planned for and met under the pressure of a real event is what makes the difference between successful (uniformly applauded) and failing (widely criticised) crisis responses. In some instances they make the difference between lives saved versus lives lost. As such, these challenges can form the basis for designing, maintaining and evaluating crisis response capacity in organisations, governments and communities.

Here we must make a distinction between the strategic and the operational levels of a response system. At the operational level, we find the first responders who are closest to the disaster and use their professional expertise to address the threat, minimise the consequences and provide immediate relief. At the strategic level, we find the political-administrative executives who carry political responsibility and are formally charged with providing direction, making decisions with potential long-term consequences, and are looked upon to provide guidance to the general public and the participants of the response network (explaining what are the causes, expected consequences, and best actions). Both levels face rather different challenges.

At the strategic level, political officeholders, agency leaders and other senior public executives face the following recurrent nine challenges of crisis response (for overviews, see Boin et al. 2005, 2008, 2010):

- Sense-making: diagnosing confusing, contested and often fast-moving situations correctly (with limited and often contradicting information);

- Meaning-making: providing persuasive public accounts of what is happening, why it is happening, what can be done about it, how and who is responsible for what ('t Hart and Tindall 2009);

- Decision-making: making strategic policy judgments under conditions of time pressure, uncertainty and collective stress;

- Coordinating: forging effective communication and collaboration among preexisting and ad hoc networks of public, private and sometimes international actors (Hilliard 2000);

- Circumscribing: scoping the nature and duration of crisis support that will be provided and determining principles for targeting and rationing such support among often ill-defined social and territorial 'victim' communities;

- Consolidating: switching government and society back from response mode to recovery and 'business as usual', yet doing so without a loss of attention and momentum in delivering long term services to those who are eligible;

- Account-giving: managing the process of expert, media, legislative and judicial inquiry and debate that tends to follow crises and disasters in such a way that responsibilities are clarified and accepted, destructive blame games are avoided and a degree of catharsis is achieved;

- Learning: making sure that the organisations and systems involved in crisis management engage in critical, non-defensive modes of self-scrutiny and draw evidencebased and reflective lessons for their future performance rather than politics-driven and knee-jerk ones (cf. Birkland 1997; Stern 1997; Deverell 2010); and

- Remembering: publicly acknowledging that many crises and disasters are traumatic experiences for victims, responders and the organisations and communities involved, and responsively accommodating their desires that the community should 'never forget' ('t Hart, Ullberg and Kofman-Bos 2005).

At the tactical/operational level, incident commanders and operations managers face a somewhat different cluster of crisis response 
challenges (Flin 1996; Flin and Arbuthnot 2002; Flin, O'Connor and Crichton 2008):

- Diagnosing and deciding: Forming an accurate picture of the nature and extent of the threat and/or damage under conditions of time pressure and incomplete information; choosing a sensible and feasible initial response approach; and continuously updating both in light of changing circumstances or additional information becoming available;

- Mobilising and organising: Soliciting the types and levels of operational resources necessary to meet the demands of the situation in a speedy yet orderly fashion, and deploying them in a timely and orderly fashion;

- Containing and mitigating: Using available resources effectively and efficiently to contain (and if possible reduce/eradicate) the agent(s) of threat and destruction so as to minimise the damage to lives and property;

- Informing and empowering: Transmitting accurate, timely and actionable information upward, outward and downward within the crisis response structure, as well as to relevant citizens and communities, designed to enable these actors to make informed crisis response decisions within their respective domains of involvement; and

- Coordinating and collaborating: Making sure different units, organisations and disciplines involved in front-line crisis responses work together effectively and in a sustainable way, both within and across the public and private/community sectors.

\section{Identifying 'Good Practices'}

Well-documented examples of good practice in crisis planning (again: this does not mean flawless or entirely undisputed) can be found in empirical studies of large-scale crises and disasters. For instance, the city of London responded well to the 2005 underground bombings (Alexander 2010). New York City re- sponded as good as may be expected to the 9/11 disaster (though afterwards there was major controversy between the fire-fighters union and City Hall over the poor quality of the NYFD's poor communications equipment, which the union claimed had contributed to its extraordinarily high death toll). The state of Louisiana worked well with its neighbouring states and the federal government when Hurricane Gustav threatened the Gulf Coast in 2008 (Boin and Egan, forthcoming). Although we do not yet have controlled testing of good practices in large- $\mathrm{N}$ designs, for the time being the numerous in-depth studies of individual cases and a range of small-N case comparisons (eg, Leonard 2010; Leonard and Howitt 2009; Rosenthal, Charles and 't Hart 1989; Rosenthal, Boin and Comfort 2001; Helsloot, Comfort and Jacobs, forthcoming) have enabled scholars to identify the probable features of effective crisis planning and preparation.

Firstly, it combines a generic, all-hazards approach with a suite of specific contingency plans for well-selected priority crisis scenarios. Good preparation is based on the realisation that each crisis and disaster is unique and may take on unknown (and unknowable) proportions. At the same time, it aims to build organisational capacities to deal with known risks that can be expected to occur.

Secondly, it focuses not on outputs (paper produced to meet legal obligations) but on the process of building a program of carefully aligned activity clusters, including: ongoing risk monitoring; top-to-bottom and continuous education/training of personnel; vicarious testing and learning through regular, rigorous table-top and field exercises; and building and maintenance of productive working relationships and mutual trust between (key nodes in) the widest possible spectrum of units and organisations that may become involved in crisis response.

Thirdly, effective crisis planning manages public expectations by acknowledging the inherent trade-offs of crisis management, for example, concerning the price of safety through optimal prevention and the willingness to pay for it by key stakeholders. It also draws attention to the inherent limitations of official 
crisis responses, for example, during the initial stages of mega fires and other types of truly catastrophic crises and disasters. It entails proactive, rich and two-way communication with relevant stakeholder and citizen communities. Crisis planning should involve more than just making sure that the government sector knows what to do in the event of crises and disasters. Enhancing community resilience and planning the interface between government, business and community sectors in crisis response should be part and parcel of the planning process. This presupposes levels of cross-sectoral involvement and dialogue that are neither self-generating nor self-sustaining. It requires community participation in crisis planning, particularly within high-salience, 'at risk' communities.

Finally, crisis planning efforts need to be continuously monitored, updated and adjusted in the light of experiences from exercises and operations, as well as analysis of experiences in other jurisdictions at home and abroad. The latter is particularly relevant in jurisdictions that themselves have little or no recent emergency experiences.

\section{Avoidable Failures in Current Government Practices}

Unfortunately, many governments appear illprepared to meet these key strategic and operational challenges and emulate such good practices. This at least is the picture that emerges from many official post-mortems and detailed academic studies of large-scale disasters. To be sure, governments have a much better record when it comes to 'expected' crises and disasters (those that occurred before and are likely to periodically reoccur). But when it comes to unique, unexpected, unusually largescale or fast-moving threats (Chernobyl, Katrina and other mega floods; BSE; the Boxing Day Tsunami; the Icelandic volcanic ash cloud) the response often appears to fall short. Well-known and avoidable pathologies too often bedevil the response to low-frequency, highimpact incidents:

\section{Bad Planning}

Disaster plans are potentially essential tools for concentrating the minds of office-holders and organisations in times of crisis. In preparing for adversity, recording procedures, routines, actors, and venues in thick and detailed plans helps to prepare for contingencies. Such plans work especially well for predictable, routine disturbances, when uncertainty and time pressure are relatively low and the scale of threat limited. A major crisis is qualitatively different. The pervasive surprise, uncertainty and overwhelming scale that characterise major crises and disasters tend to shatter some of the key presumptions of most existing plans. This is not to say that crisis planning is useless. On the contrary, when done properly it serves important start-up and network-building functions (see further below). But by attaching too much value to the plan as document, a false sense of security can emerge. This is especially the case in so-called 'fantasy documents' - contingency plans that rest on unrealistic, overoptimistic assumptions (Clarke 1999). Fantasy documents underrate the damage and chaos that some crises and disasters entail, and overrate the capacity of organisations and governments to quickly and effectively minimise their impact. They do not consider worst-case scenarios. They suffer from risk selection bias, in that they are unduly focused on a narrow set of seemingly most salient contingencies (eg, floods in Bangladesh, winter havoc in northern Ontario, terrorist attacks in post 9/11 Washington, bushfires in Victoria).

\section{An Obsession with Full Information}

Once a sense of crisis holds policy-makers in its grip, they typically enter upon a quest for ever more information. The plans suggest that all information should flow to the strategic and operational command centres that are the hubs in the response operation. Unfortunately, hard facts and figures tend to be in short supply during a crisis. Moreover, facts and figures often turn out to be less than secure, which triggers new searches for better information. The subsequent deluge of incoming, often patchy or even 
contradictory, data is incredibly hard to analyse. Even though the search for a complete and accurate picture is understandable, the time and energy devoted to bringing it about can paralyse response operations. In crises and disasters, there needs to be the capacity to improvise and make intuitive judgments on the basis of incomplete information. Refusing to make urgent decisions in the absence of complete and accurate information is an avoidable failure.

\section{Communication Breakdowns}

Crisis management critically depends on smooth communication flows within and between organisations. Moreover, they need to communicate with the external environment, directly or through the media. During most crises, however, communication often breaks down for a variety of reasons, only some of which are purely technical (equipment). In many cases, the most debilitating communication barriers are cultural: lack of pre-existing communications channels and routines, lack of trust between organisations, predominance of narrow, mono-disciplinary or localised definitions of what is going on and what is important to know and divulge to others. The avoidable failure is to concentrate crisis planning efforts exclusively on technical solutions, rather than addressing the cultural factors inhibiting communication flows (Fearn-Banks 1996; Sonnenfeld 2000; Millar and Heath 2004).

\section{Total Reliance on Command and Control}

A persistent planning myth has it that any crisis management operation is best organised in a military-styled command and control mode. However, the first phase of a crisis will inevitably be marked by a lack of information, communication and coordination, and at that time it is impossible to control each and every move of first responders (Barton 1969; Rodriguez, Quarantelli and Dynes 2006). The same goes for multi-theatre, fast moving crises and disasters like bushfires, when all too centrally organised response systems break down, as time is lost pushing information and requests up the line and waiting for orders to come down (see further Leonard's paper in this same issue). Effective responses in such extreme circumstances are necessarily improvised, flexible and networked (rather than planned, standardised and centrally led). They are driven by the initiative of operational leaders and the strength of the pre-existing ties between the teams and organisations they represent (Eisenhardt 1993; Hilliard 2000; Mission Centered Solutions 2003; Buck, Trainor and Aguirre 2006; Moynihan 2007, 2009; Lutz and Lundell 2008). Any attempt on the part of strategic decision-makers to plan and command each and every aspect of crisis response impedes flexibility and local initiative and constitutes an avoidable failure.

\section{Underestimating that the Medium is the Message}

There is no doubt that media provide crucial channels of communication to both the crisis response network and the outside world. But they do more than that. They set the stage on which the performance of crisis managers will be evaluated (Streitmatter 1997; Miller and Goidel 2009). In addition, the Internet and its social networking sites have added a whole new layer of opportunities as well as complications in organising communication and 'meaning making' in times of crisis, which need to be addressed and not willed away in crisis planning processes. Reporters will not abandon their critical faculties, or ignore the commercial pressures they are under to produce news that sells, just because the story of the day is one of disaster and tragedy. When media turn critical, crisis managers' disappointment at this 'betrayal' often spills over into an 'us-versusthem' mentality towards journalists pervading the spirit if not the letter of crisis planning. Such gross underestimation of the power of media forces constitutes an avoidable failure (Fearn-Banks 1996).

\section{Underestimating the Crisis After the Emergency}

The most complex leadership challenges of crisis management often arise after the operational 
demands of the incident response have been addressed (Boin, McConnell and 't Hart 2009). When exhausted policy-makers are ready to return to the 'normal' issues of running their organisations and governments, they discover that most emergencies cast a long shadow (Rosenthal et al. 1994; 't Hart and Boin 2001). They will have to engage in the politics of crisis management. These involve scoping and implementing recovery programs in a climate of trauma and, often, recrimination. They also involve calls for inquiries, accountability, blame and liability. In addition, they are about the 'learning' and 'change' that is expected to occur as a result of the crisis experience - processes in which there can be considerable gains as well as losses for many stakeholders. The activities of victim groups, journalists, lawyers, parliamentary oppositions and inquiry bodies time and again demonstrate just how important that phase is. Underestimating the potential for a 'crisis after the emergency' is yet another avoidable failure of crisis planning and preparation.

\section{Response Organisations: The Need for a Normative Standard}

The research on emergency response organisations makes clear that there are no easy, one-size-fits-all generalisations on offer when it comes to the crisis roles and performance of these critically important organisations. Not only do crises and disasters come in a great variety of forms posing potentially different demands upon one and the same organisation (eg, the difference between the roles of fire brigades during bushfires, earthquakes, major urban riots, or CBR [chemical, biological, radiological] incidents), they also tend to mobilise a great number of different organisations with different levels of involvement, capacity and performance. Each crisis (unique in itself) requires a network that is likely to be unique.

This variety is well captured in the classic typology of organisational responses to disaster proposed by Russel Dynes (1970). Dynes' classification rests on two pivotal dimensions: Is an organisation's involvement in a crisis or disas- ter part of that organisation's core tasks or not? Do the organisation's response operations occur within its pre-existing structure or does the organisation need to adapt its structure or size? Combined, these dimensions produce a fourfold typology (see Table 1). Each cell harbours a cluster of organisations with similar characteristics and crisis response predicaments.

Established organisations typically constitute the first line of response to an unfolding acute crisis. They operate in the real time of the events themselves (cf. Roe and Schulman 2008). They can often make a real 'life and death' difference through the speed, scope, and effectiveness of their response, which, in turn, depend on the quality of their internal communications and the training of their first responders. These organisations have high public visibility and usually enjoy strong public support. They consider themselves to be at the heart of crisis management, and they typically spend a considerable part of their resources on crisis planning, preparation and training.

Extending organisations play a crucial role in the secondary response to a crisis, ie, dealing with the economic, social and psychological impacts of crises and disasters on the lives of victims/communities. Disaster response is not necessarily part of their core business, though it typically is covered within their broader mandates. Their level of involvement in crisis planning is often fairly limited. They are usually part of 'the bureaucracy' that citizens experience on a day-to-day basis. The public standing they enjoy prior to the crisis may vary considerably but more often than not is considerably lower than that of the established crisis services. Extending organisations face the challenge of being called to switch from sequential processing of individual cases to high-speed, parallel processing of large numbers of cases, and from well-structured, predictable cases to un-usual, un-regulated cases. This requires improvisation and departures from standard operating procedures.

Expanding organisations are typically human services organisations within and outside government that have crisis management as a key (though not core) component of their mission, yet have the majority of their personnel 
Table 1. Types of Organisations in Disaster Response Processes (Dynes 1970)

\begin{tabular}{lcc}
\hline Tasks Structure & \multicolumn{1}{c}{ Regular } & Non-regular \\
\hline Existing & Type 1: Established (eg, police, fire, & Type 2: Extending (eg, housing, family and \\
New & ambulance services) & social services, tax, schools) \\
& Type 3: Expanding (eg, Red Cross, & Type 4: Emerging (eg, Bushfire Recovery \\
& Salvation Army) & Authority, disaster victims' organisations) \\
\hline
\end{tabular}

routinely committed to other tasks (they remain 'dormant'). Volunteer-dominated expanding organisations such as the Red Cross perform support roles for the established organisations but may also provide public services in their own right. Their performance stands or falls with their ability to maintain their 'surge capacity,' both quantitatively and qualitatively.

Emergent organisations are literally born during crises and disasters. Their emergence may be anticipated in formal planning as enhancing the disaster response (ie, coordinating bodies, incident command centres). But they mostly emerge spontaneously and unexpectedly, often in reaction to hitherto unplanned needs or perceived deficiencies of the existing response efforts (ie, victims groups, recovery networks). Their mandates tend to be ambiguous, their authority structures unclear and their processes unstructured. They emerge and try to 'add value' in what often is an already densely populated organisational space. This is known to create tensions with some of the pre-existing organisations.

The Dynes typology makes it clear that the quality of disaster preparedness and response within any community depends on much more than the structure and performance of the established (type one) organisations, eg, the fire agencies. There is no denying that their successes and failures tend to be the most conspicuous and consequential during the initial phase of the crisis response. And so it is their performance that tends to get the most scrutiny during post-mortems and inquiries. However, an exclusive focus on established organisations of the classic emergency services when evaluating or improving public crisis response capacities is far too narrow. All four types of organisations become pivotal. This becomes particularly clear when the first-line operational response stage gives way to the much longer, more complex, and often more contentious secondary response and recovery stages. Official inquiries into the causes of a disaster often reveal the importance of regulatory/enforcement practices by a wide range of type one, two and sometimes three agencies.

If each organisational type faces distinctive challenges during a disaster, the ways in which their performance is assessed should reflect this. Each type's specific strengths and weaknesses need to be understood. The same goes for the nature and quality of their interrelationships (see further down). What is needed, in short, is a differentiated approach to defining and achieving 'good practice' in organising for crisis and disaster (Alexander 2005). However, it is also important to realise that some organisations harbour within them units corresponding to different types in the typology. For example, the Victorian Department of Sustainability and Environment (DSE) harbours an 'established' organisation (its fire brigade) within an 'extending' one, creating a specific set of potential challenges and tensions totally different from those facing the Country Fire Authority, which can be seen as a hybrid of an 'established' and an 'expanding' organisation.

In their efforts to identify good practices, academics and practitioners have displayed a keen interest in the principles and practices of what are known as High Reliability Organisations (HROs) (Sagan 1993; LaPorte 1996; Roe and Schulman 2008). The HRO label was coined by a group of Berkeley scholars who studied a set of organisations that deal with dangerous technologies that should not fail (nuclear power stations, battleships, and air traffic control systems). ${ }^{2}$ The observed organisations managed to avoid major accidents over long periods of time (Roberts 1993; Weick and Sutcliffe 2007). 
Although HROs are mainly geared to preventing incidents from escalating into full-blown crises and disasters, it stands to reason that such principles and practices would also improve the capacity to operate effectively in crisis conditions.

HROs achieve high levels of safety while consistently maintaining performance by means of a sophisticated set of risk management practices that are deeply engrained in their organisational cultures. It is important to note that they differ widely in terms of their formal structures and governance arrangements; it is their culture - the software, not the hardware of the organisation - that makes the biggest difference. This culture allows HROs to recognise weak signals of trouble ahead, to design and apply problem resolutions in real-time operations, and to maintain effective internal communications under duress. The characteristics of an HRO include: a preoccupation with failure leading to continual tracking of deviations and small failures based on a non-negotiable value of 'safety first'; resisting oversimplification of operational tasks and routines by paying heed to operational realities and requirements in the making and implementation of managerial policies; a norm that both operators and managers need to possess deep knowledge of how the technological and operating systems function; managerial deference to operator expertise in managing day-to-day processes as well as in dealing with non-routine problems and disturbances; an ethos of resistance to efficiency pressures in order to maintain redundancies and 'slack resources' essential to flexibility in coping with the unexpected (cf. Landau and Chisholm 1995); and finally rigorous reporting and established procedures for learning from incidents and near misses.

HROs are unconventional in that they expect people to make mistakes and systems to fail in unimagined ways (cf. Reason 1990). They make learning from incidents and mistakes the centerpiece of their internal processes. Their leaders make reporting errors and questioning assumptions across hierarchical levels safe, even desired. Continuous updating of risk awareness in this mindful way minimises the likelihood of large failure, speeds recovery through intelligent improvisation, and protects the capacity for organisational learning from being subverted by post-incident finger pointing and buck passing.

The question is whether the practices found in a few organisations translate into a standard for all organisations, including governmental organisations and interorganisational networks, that deal with dangerous technologies. There are many reasons to doubt this (for vigorous debate, see LaPorte 1994; cf Sagan 1993). The investigation into the Columbia space shuttle disaster shows why assuming so can be misleading (CAIB 2003; Boin and Schulman 2008). That inquiry elevated the principles of HROs to a standard and used this standard to evaluate the performance of National Aeronautics and Space Administration (NASA), concluding that the space agency was not an HRO. It is unclear, however, if this disaster would have been prevented had NASA qualified as an HRO. Using HRO characteristics as a normative model for crisis response organisations (that do not deal with high-risk technologies) therefore has its limitations. They are a set of heuristically powerful principles, but not a golden standard than can just be copied from one type of challenge (major accident prevention) to another (crisis preparedness and response), and from the relative simplicity of the one focal, hierarchical organisation to the fuzzy complexity of emergency response networks.

\section{Creating Effective Response Networks}

Major crises are, almost by definition, not tackled by single organisations but by networks of organisations, which cut across disciplinary, jurisdictional and public-private sector boundaries (Hilliard 2000; Kapucu 2008). The crisis response capacity of a society is, therefore, to a very considerable extent determined by the breadth and depth of interorganisational relations in its crisis management systems. Just having high-performing components within that system is not good enough; it is the linkages between components that make or break systemic resilience. It is not easy to achieve full-blown collaboration and partnership in 
crisis management (Waugh 2006). Empirical studies of crisis management networks show that pivotal actors accord it low priority, that tribal identities are strong, particularly among the uniformed services, and that the divide between fulltime and volunteer crisis management workers can be persistent (Wise and McGuire 2009).

The consequences of suboptimal interorganisational relations in crisis response networks are clear (one only has to think of the botched response to Hurricane Katrina). If the response network falters, even the simplest tasks (bringing bottles of water to the New Orleans Superdome) may become unbelievably complicated. Networks fall apart when: information does not travel smoothly back and forth within the system, creating blind spots, gaps and biases in sense-making/diagnosis. This reduces the early warning/quick response capacity of the system and may lead to significant misallocation of scarce response resources; organisations continue to run their own race, producing disjointed response operations that are confusing to citizens and other stakeholders; and time-consuming conflicts emerge over division of labour, 'incident controller' and 'lead agency' roles, and the choice of methods of operation.

At the other end of the spectrum, there are also well-documented instances of intensive and harmonious cooperation in networks and partnerships characterised by high levels of information sharing and mutual trust (Hilliard 2000; Moynihan 2007, 2009; Oloruntoba 2010). This research into effective responses has produced different, but overlapping sets of conditions and mechanisms.

One critical condition for an effective network is that the organisations involved perform their activities in a coordinated fashion. The articulation of a set of common purposes, based on a deep-rooted awareness of interdependency among the parties involved is helpful. An agreed upon authoritative decision-making and conflict resolution structure at the level of the network as a whole also helps. In the United States (US), the fire-fighting community developed the Incident Command System (ICS). ICS is a 'mechanism for inter-organisational coordination designed to impose order on certain dimensions of the chaotic organisational environments of disasters' (Buck, Trainor and Aguirre 2006). It has been adopted across the spectrum of emergency response organisations as the standard for network coordination.

Another condition for effective response networks is the absence of political infighting between organisations. Research has shown time and again that it would be naïve to presume that a crisis acts as a common enemy that induces seamless and harmonious linkages between all the organisations involved in the response. On the contrary, disaster experts have coined the term 'battle of the Samaritans' to denote the frequently observed phenomenon of overt interorganisational competition and disagreement at or around disaster sites (Rosenthal, 't Hart and Kouzmin 1991). By defining, funding and evaluating network-level projects and outcomes to supplement and partly replace existing funding/accountability streams of individual organisations, incentives can be created to take collaboration seriously, and improve interpersonal and interorganisational trust prior to crises.

A third condition is that the right organisations are part of the response network. This may sound rather obvious, but a common finding is that the circle of organisations actively involved in crisis response networks is drawn too narrowly, focusing first and foremost on type one and type three organisations with much more patchy participation of type two organisations, and insufficient thought devoted to the emergence of type four organisations during the course of a crisis. Inclusive membership relative to the tasks at hand presupposes a sensible determination of what configuration of organisations (public and private; established and expanding and extending and emergent) is needed and what arrangements between them provide the most effective relationships to perform a needed function.

Finally, interpersonal trust between key representatives of different units is a crucial asset in the event of a major crisis, as a source of 'short cuts' and an informal coordination mechanism. For example, evaluations of the Incident Command System show that it works 
best when it is not exclusively interpreted as a way of imposing hierarchical, top-down control on a disaster response operation, but also as a device for forging joint action that capitalises on pre-existing network relationships (Moynihan 2009). Such trust is inherently vulnerable to the coming and going of key individuals. But there is no alternative: when such trust is not actively cultivated and maintained organisations involved in crisis response will perhaps work in parallel, but not in tandem, and will fail to reap the benefits that only integration of operations can bring.

\section{Building an Effective Response System: The Low-Hanging Fruit}

Redesigning crisis management systems or organisations usually happens as a result of the sheer momentum for change created by the occurrence of a recent high-impact tragedy. Unfortunately, there is plenty of research to suggest that such crisis-induced reforms may create as many vulnerabilities as they seek to eliminate - particularly when they are too narrowly focused on 'winning the most recent war' (Boin and 't Hart 2003; Brandstrom, 't Hart and Bynander 2004). Many crisis management researchers have observed that the world has entered the era of 'mega crises' or 'catastrophic crises and disasters' whose force and magnitude defy even the best laid plans and the most robust response systems (Beck 1992; Helsloot, Comfort and Jacobs, forthcoming). In the light of new and unknowable threats, it is hard to develop a realistic assessment of what can and cannot be expected from governments and crisis services in the face of mega-crises. One cannot not infer from the mere occurrence of a high-casualty tragedy such as Black Saturday that existing crisis management systems therefore must have failed and need far-reaching structural reforms.

At the same time, there are lessons to be learned that will enhance the effectiveness of the response to any type of crisis or disaster. It is this low-hanging fruit that we identify in this section. We begin by formulating two key assumptions and then move on to iden- tify the most basic mechanisms of effective response systems. Our first assumption is that the oft-observed importance of 'hardware' (formal structures; technical equipment; legal frameworks) is overrated. It distracts attention from the often more salient and cost-effective, yet less symbolically powerful 'software' factors (leadership, training, network building, organisational culture). At worst, structural reform exercises result in one set of institutional weaknesses being replaced by another, at great costs to taxpayers. A case in point is the formation of the Department of Homeland Security in the US following the 9/11 attacks, which apparently contributed to the massive crisis management failure regarding hurricane Katrina. Secondly, we propose that it is not formal structures but the quality of communication, coordination and collaboration within, across and beyond emergency services that matter most in shaping the quality of crisis responses. Yes, troublesome information sharing and poor coordination of decisions and operations lie at the heart of many crisis response pathologies. But these do not go away when organisations are chopped and changed, for instance by forcibly merging them into 'superagencies'. Like all mergers, such 'solutions' impose huge transition costs. They entail protracted uncertainty that may depress rather than enhance the system's overall response capacity during the transition period, and even when that period is completed there are no guarantees that the merger as such will produce added value. Without cultural integration occurring, the mere changing of formal structures is immaterial: what were once interorganisational battles will continue as intraorganisational battles.

Instead of going down the structural reform path, it is more helpful to identify a select set of administrative principles that have served policy-makers well in organising and managing a crisis response network. These principles do not aim to prepare a planned response for every conceivable type of crisis. Quite the contrary. Recognising that true crises and disasters are always unforeseen and often unimaginable, these principles aim to enhance the collective resilience. They make it possible to rapidly form response networks that are most 
adequately equipped to deal with any sort of crisis (regardless of its origin).

It all begins with the basic functions that every crisis response network will need to perform: warning; mobilisation; registration; evacuation; sheltering; crisis medical care and after care; search and rescue; protection of property; information dissemination (Quarantelli 1988). These generic functions should be planned for, staffed by trained officials, ready to use, and updated through periodic testing. In most (but not all) Western countries, these mechanisms do not present the biggest problem as many improvements have been made in recent years. The response to Hurricane Katrina, however, demonstrates that nothing can be taken for granted in this regard.

Secondly, high-level policy-makers must be trained to deal with crises and disasters (Dror 1988; Lagadec 1997; Carrel 2000). They must learn the regularities of crisis management: the political and organisational issues that will emerge, the faltering information flows, the complex dilemmas and the impossible choices, the tolls of stress and the search for scapegoats and 'lessons'. They must learn to use simple checklists that will improve their crisis performance: balance short and long-term effects of a decision; make sure you hear contrarian views; leave operational decisions to the professionals; stick with the political decisions that must be made - and make them; facilitate emerging coordination rather than imposing ready-made designs; engage with the media in a proactive manner.

Thirdly, frequent and rigorous crisis exercises and simulations make for better crisis management performance. The mayor of New York City, Rudolph Giuliani, credited the series of crisis management exercises held before the 9/11 attacks in explaining the effective response of the New York City response network. Experts agree (Cottam and Preston 1997). Regular simulation exercises nurture awareness of crisis management complexities, hone decision-making skills, and allow members of the response network to get to know, understand and respect each other. Not having this is one of the principal causes of crisis response failures.
Effective crisis preparedness includes the forging of relationships among response agencies, as well as with media representatives, external stakeholders, and a variety of experts. Once a crisis has occurred there is usually no time to look for the right people and interact with them on a basis of trust. Effective crisis response relies strongly on pre-existing cooperative networks built and maintained painstakingly during the preceding years. Strategic policy-makers should do everything to foster the growth of such networks. They should not tolerate the persistence of non-contact, silo mentalities and bureaucratic turf wars in interorganisational relations within the crisis management domain.

Policy-makers must prepare more intensively for the post-crisis phase, which is glaringly overlooked in most conventional disaster exercises. They must have in place a system that facilitates the accountability process that will most likely follow any major crisis. They should at least consider the involvement of external bodies of expertise that can manage their own organisational learning process (these bodies can be also be involved in the study of smaller scale incidents and near misses).

Crisis management systems should be audited on a regular basis by independent experts. The critical examination by outsiders is an essential quality assurance system. It introduces accountability in a normally obscure area that only comes under scrutiny after disasters have occurred. Audits as well as lesson-drawing exercises based on comparative analysis of experiences in other jurisdictions force the crisis management fraternity to explain why the system looks the way it does, and to reflect on the strengths and weaknesses of current arrangements. They generate new insights that can make the system more effective.

System-wide crisis preparedness will not happen without the active, continuous involvement and visible commitment of politicaladministrative elites. They must nurture a culture of inquiry, in which everybody is invited to consider vulnerabilities and propose better ways of organising a resilient system. Their words and deeds must signal that crisis 
management is a crucial activity - all the time (Carrel 2000).

\section{Endnotes}

1. An earlier version of this article, written by Paul 't Hart was submitted as expert evidence to the Royal Commission on the Victorian Bushfires.

2. A variety of different types of organisations such as electricity firms and hospitals have since been added to the HRT empirical case directory. For an Australian account, see Hopkins (2009).

\section{References}

Alexander, D. 2005. 'Towards the Development of a Standard in Emergency Planning.' Disaster Prevention and Management 14(2):158-175.

Alexander, D. 2010. 'Rapid Adaptation to Threat: The London Bombings of 7 July 2005.' In Designing Resilience: Preparing for Extreme Events, eds L.K. Comfort, A. Boin and C. Demchak. Pittsburgh: Pittsburgh University Press.

Barton, A.H. 1969. Communities in Disaster: A Sociological Analysis of Collective Stress Situations. Garden City, NY: Doubleday.

Beck, U. 1992. Risk Society: Towards a New Modernity. London: Sage Publications.

Birkland, T. 1997. After Disaster: Agenda-Setting, Public Policy, and Focusing Events. Washington: Georgetown University Press.

Boin, A. and J. Egan. Forthcoming. 'Hurricane Gustav.' In Mega Crises, eds I. Helsloot, L.K. Comfort and B.D. Jacobs Springfield, IL: Charles C Thomas.

Boin, A. and P. 't Hart. 2003. 'Public Leadership in Times of Crisis: Mission Impossible?' Public Administration Review 63(6):544-553.

Boin, A. and P. Schulman. 2008. 'Assessing NASA's Safety Culture: The Limits and Possibilities of High Reliability Theory.' Public Administration Review 68(6):1050-1062.

Boin, A., P. 't Hart, E. Stern and B. Sundelius. 2005. The Politics of Crisis Management: Public Leadership under Pressure. Cambridge: Cambridge University Press.

Boin, R.A., A. McConnell and P. 't Hart, eds. 2008. Governing After Crisis: The Politics of Investigation, Accountability and Learning. Cambridge: Cambridge University Press.
Boin, R.A., A. McConnell and P. 't Hart. 2009. 'Crisis Exploitation: Political and Policy Impacts of Framing Contests.' Journal of European Public Policy 16(1):81-106.

Boin, R.A., A. McConnell and P. 't Hart. 2010. 'Crisis Leadership.' In: Political and Civic Leadership: A Sage Reference Handbook, ed. R.A. Couto. London: Sage.

Brandstrom, A., P. 't Hart and F. Bynander. 2004. 'Governing by Looking Back: Historical Analogies and Crisis Management.' Public Administration 82(1):191-110.

Buck, D.A., J.E. Trainor and B.E. Aguirre. 2006. 'A Critical Evaluation of the Incident Command System and NIMS.' Journal of Homeland Security and Crisis Management 3(3):127.

CAIB [Columbia Accident Investigation Board]. 2003. Columbia Accident Investigation Report. Burlington, ON: Apogee Books.

Carrel, L. 2000. 'Training Civil Servants for Crisis Management.' Journal of Contingencies and Crisis Management 8(4):192-196.

Clarke, L. 1999. Mission Improbable: Using Fantasy Documents to Tame Disaster. Chicago: University of Chicago Press.

Cottam, M. and T. Preston, eds. 1997. 'An Overview of the Value and Use of Simulations in the Academic, Business and Policy Communities.' Journal of Contingencies and Crisis Management 5(4):195-197.

Deverell, E. 2010. Crisis-Induced Learning in Public Sector Organisations. Stockholm: CRISMART.

Dror, Y. 1988. 'Decision-Making under Disaster Conditions.' In Managing Disaster, L.K. Comfort. Durham: Duke University Press.

Dynes, R. 1970. Organized Behaviour in Disaster. Lexington MA: Heath Lexington Books.

Eisenhardt, K.M. 1993. 'High Reliability Organizations meet High Velocity Environments.' In New Challenges to Understanding Organizations, ed. K.H. Roberts. New York: MacMillan, 117136.

Fearn-Banks, K. 1996. Crisis Communications: A Casebook Approach. Mahwah, NJ: Lawrence Erlbaum Associates.

Flin, R.H. 1996. Sitting in the Hot Seat: Leaders and Teams for Critical Incidents. Chichester: Wiley.

Flin, R. and K. Arbuthnot, eds. 2002. Incident Command: Tales from the Hot Seat. Aldershot: Ashgate.

Flin, R, P. O'Connor and M. Crichton. 2008. Safety at the Sharp End: A Guide to Non-Technical Skills. Aldershot: Ashgate. 
Helsloot, I., L.K. Comfort and B.D. Jacobs, eds. Forthcoming. Mega Crises. Springfield, IL: Charles C Thomas.

Hilliard, M. 2000. Public Crisis Management: How and Why Organizations Work Together to Solve Society's Most Threatening Problems. Lincoln: Writer's Club Press.

Hopkins, A., ed. 2009. Learning from High Reliability Organisations. Sydney: CCH.

Kapucu, N. 2008. 'Collaborative Emergency Management: Better Community Organizing, Better Public Preparedness and Response.' Disasters: The Journal of Disaster Studies, Policy, and Management 32(2):239-262.

Lagadec, P. 1997. 'Learning Processes for Crisis Management in Complex Organizations.' Journal of Contingencies and Crisis Management 5(1):24-31.

Lagadec, P. 2009. 'A New Cosmology of Risks and Crises: Time for a Radical Shift in Paradigm and Practice.' Review of Policy Research 26(4):473486.

Landau, M. and D. Chisholm. 1995. 'The Arrogance of Optimism: Notes on Failure-Avoidance Management.' Journal of Contingencies and Crisis Management 3(2):67-80.

LaPorte, T.R. 1994. 'A Strawman Speaks Up: Comments on The Limits of Safety.' Journal of Contingencies and Crisis Management 2(4):207211.

LaPorte, T.R. 1996. 'High Reliability Organizations: Unlikely, Demanding and at Risk.' Journal of Contingencies and Crisis Management 4(2):6071.

LaPorte, T.R. 2007. 'Critical Infrastructure in the Face of a Predatory Future: Preparing for Untoward Surprise.' Journal of Contingencies and Crisis Management 15(1):60-64.

Leonard, H. 2010. Organising Response to Extreme Emergencies. Paper submitted to the Royal Commission on the Victorian Bushfires, Melbourne, 30 April.

Leonard, H. and A. Howitt, eds. 2009. Managing Crises: Responding to Large-Scale Emergencies. Washington: Congressional Quarterly Press.

Lutz, L.D. and M.K. Lundell. 2008. 'Incident Command System as a Response Model Within Emergency Operation Centers During Hurricane Rita.' Journal of Contingencies and Crisis Management 16(3):122-134.

Millar, D.P. and R.L. Heath. 2004. Responding to Crisis: A Rhetorical Approach to Crisis Communication. Mahwah, NJ: Lawrence Erlbaum Associates.
Miller, A. and R. Goidel. 2009. 'News Organizations and Information Gathering During a Natural Disaster: Lessons from Hurricane Katrina.' Journal of Contingencies and Crisis Management 17(4):266-273.

Mission Centered Solutions. 2003. Southern California Firestorm 2003: Report for the Wildland Fire Lessons Learned Center. Arizona: Mimeo.

Moynihan, D.P. 2007. From Forest Fires to Hurricane Katrina: Case Studies of Incident Command Systems. Washington, DC: IBM Center for Business and Government.

Moynihan, D.P. 2009. 'The Network Governance of Crisis Response: Case Studies of Incident Command Systems.' Journal of Public Administration Research and Theory 19(6):895-915.

OECD [Organisation for Economic Cooperation and Development]. 2003. Emerging Risks in the $21^{\text {st }}$ Century: An Agenda for Action. Paris: OECD.

Oloruntoba, R. 2010. 'An Analysis of the Cyclone Larry Emergency Relief Chain: Some Key Success Factors.' International Journal of Production Economics 126(1):85-101.

Perrow, C. 1984. Normal Accidents-Living with High-Risk Technologies. Princeton, NJ: Princeton University Press.

Perrow, C. 2007. The Next Catastrophe. Princeton, NJ: Princeton University Press.

Quarantelli, E.L. 1988. 'Disaster Crisis Management: A Summary of Research Findings.' Journal of Management Studies 25(4):373-385.

Reason, J. 1990. Human Error. Cambridge: Cambridge University Press.

Roberts, K., ed. 1993. New Challenges to Understanding Organizations. New York: MacMillan.

Rodriguez, H., E.L. Quarantelli and R.R. Dynes, eds. 2006. Handbook of Disaster Research. New York: Springer.

Roe, E. and P. Schulman. 2008. High Reliability Management: Operating on the Edge. Stanford: Stanford University Press.

Rosenthal, U. 1998. 'Future Disasters, Future Definitions.' In What is a Disaster: Perspectives on the Question, ed. E.L. Quarantelli. London: Routledge, 146-159.

Rosenthal, U., M.T. Charles and P. 't Hart, eds. 1989. Coping With Crises: The Management of Disasters, Riots and Terrorism. Springfield, IL: Charles Thomas.

Rosenthal, U., P. 't Hart and A. Kouzmin. 1991. 'The Bureau-Politics of Crisis Management.' Public Administration 69(2):211-233.

Rosenthal, U., R.A. Boin and L.K. Comfort, eds. 2001. Managing Crises: Threats, Dilemmas, 
Opportunities. Springfield, IL: Charles C. Thomas.

Rosenthal, U., P. 't Hart, M. Van Duin, A. Boin, M. Kroon, M. Otten and W. Overdijk. 1994. Complexity in Urban Crisis Management: Amsterdam's Response to the Bijlmer Air Disaster. London: James and James.

Sagan, S.D. 1993. The Limits of Safety: Organizations, Accidents and Nuclear Weapons. Princeton: Princeton University Press.

Sonnenfeld, S. 2000. 'Media Policy - What Media Policy?' In Harvard Business Review on Crisis Management. Boston, MA: HBR Press, 119 142.

Stern, E.K. 1997. 'Crisis and Learning: A Balance Sheet.' Journal of Contingencies and Crisis Management 5(2):69-86.

Streitmatter, R. 1997. Mightier Than the Sword: How the News Media Have Shaped American History. Boulder, CO: Westview Press.

't Hart, P. 1993. 'Symbols, Rituals and Power: The Lost Dimension in Crisis.' Journal of Contingencies and Crisis Management 1(1): 36-50. 't Hart, P. and A. Boin. 2001. 'Between Crisis and Normalcy: The Long Shadow of Post-Crisis Politics.' In Managing Crises, eds U. Rosenthal, A. Boin and L.K. Comfort. Springfield, IL: Charles C Thomas, 28-48.

't Hart, P. and K. Tindall, eds. 2009. Framing the Global Economic Downturn: Crisis Rhetoric and the Politics of Recessions. Canberra: ANU Press.

't Hart, P., S. Ullberg and C. Kofman-Bos. 2005. 'The Long Shadow of Disaster: Memory and Politics in Holland and Sweden.' International Journal of Mass Emergencies and Disasters 23(1):5-26.

Turner, B.A. 1978. Man-Made Disasters. London: Wykeham.

Weick, K. and K. Sutcliffe. 2007. Managing the Unexpected: Assuring High Performance in an Age of Complexity. San Francisco, CA: Jossey-Bass.

Waugh, W.L. 2006. 'Collaboration and Leadership for Effective Emergency Management.' Public Administration Review 66(2):132-140.

Wise, C.R. and M. McGuire. 2009. 'Wildland Fire Mitigation Networks in the Western United States.' Disasters 33(4):721-746. 